\title{
"Does Supplementing Traditional teaching with Computer Assisted Learning (CAL) Module Facilitates Understanding of Human Embryology in Medical Undergraduates? A Randomized Control Trial”
}

Rajan Bhatnagar ${ }^{1}$, Aseem Tandon ${ }^{1}$, Rishi Pokhrel ${ }^{1}$.

${ }^{1}$ Dept of Anatomy, Armed Forces Medical Collage, Pune- 40, India.

\begin{abstract}
Introduction: In present scenario when lesser time is being devoted to basic medical sciences, and at the same time knowledge and concepts required to be mastered by medical undergraduates increasing exponentially, structured modules and software have a potential role to play. Embryology in particular can be a subject for such modules owing to its complex dynamics and even less proportion of time available to master it. This study evaluates if supplementing traditional methods with computer-aided instruction improve students' understanding of human embryology.

Methods: The study was conducted during revision sessions before university examinations. Subjects of study were first year medical undergraduates $(\mathrm{n}=128)$, divided into two equal groups by simple randomization. Demographic data and prior academic performance of students were collected from student profile register. Revision sessions for control group were conducted using traditional methods and for test group CAL module was used. Students were evaluated by pre and post-tests consisting of 50 multiple choice answers questions each and each question fetched 0.5 marks. Independent sample t test was used for comparison of means. Opinion of students and instructors were collected using anonymous questionnaire under heads of subject-interest, appropriateness of CAL module as teaching materials, overall satisfaction and its possible effectiveness as self-learning module.
\end{abstract}

Results: Two groups showed no statistical difference in terms of sex ratio, age and prior academic performance. Pre-test showed no significant difference in mean scores of two groups, mean post-test scores on the other hand were significantly greater in test group as compared to the control group. Most of the students and instructors involved in the study graded the CAL-module as 'excellent'.

Conclusions: The study shows that traditional teaching methods supplemented with CAL module improves the understanding of developmental anatomy in medical undergraduates. Use of this module as a self-study material requires further evaluations.

Keyword: basic science education; computers/technology; developmental anatomy.

\section{INTRODUCTION}

Over the years, methods of teaching anatomy have gone through three stages, from simple observation to dissection of cadavers, and now to computer-assisted learning $(\mathrm{CAL})^{1}$.CAL and self-instructional programs provide an accessible, interactive, and flexible way of presenting curriculum material ${ }^{2}$ and can provide an effective supplement to conventional methods of teaching, particularly in subjects such as anatomy

Correspondence:

Dr. Rishi Pokhrel.

Department of anatomy, AFMC, Pune-40, India

Email:rongon28us@yahoo.com 
and physiology ${ }^{3}$. It is becoming 'a truth universally acknowledged' that the education of undergraduate medical students will be enhanced through the use of $\mathrm{CAL}^{5,6}$.

CAL can be used to supplement current teaching methods, deliver instructional material and is particularly useful in demonstrating topics which are complex or relatively difficult to access when seen in the textbook or cadaver ${ }^{6}$. McNulty et al showed that students who access the CAL resources most frequently scored significantly higher on exams compared with students who never accessed the resources ${ }^{7}$. A couple of similar studies showed that 'blended learning strategies' are superior to traditional methods alone in making students grasp the concepts of anatomy ${ }^{1,8}$. CAL is also user friendly and younger generation have positive attitude regarding the value and usefulness ofitin learning human gross anatomy ${ }^{9}$.

Teaching anatomy to both undergraduate medical students and medical graduates is in the midst of a downward spiral ${ }^{14}$. It has been our experience over years that medical undergraduates find humanembryology and more particularly developmental dynamics unyielding and inefficient in terms of time spent to score ratio. This can be explained by relatively few teaching hours dedicated to embryology and its lesser contribution in university examinationsrelative to complexity and vastness of the subject.After a brainstorming session among faculties of anatomy department at our institute, we decided to develop a CAL module on human embryology incorporating core areas of learning in form of text, figures and 3D models in addition to animation videos.

This study was conducted to test the effectiveness of this module with hypothesis that CAL module when supplemented with traditional methods of teaching can improve understanding of human embryology in medical undergraduates.

\section{METHODS}

\section{Study sample}

The subjects of this study were medical students enrolled in a batch of first year of 6-year medical undergraduatecourse (Bachelor of medicine and bachelor of surgery or MBBS) at our institute. Among
133 students in the batch five opted out of the study and total study sample consisted of 128 students. These were divided by simple randomization into two groups of equal size; group A was test group and group B control group. Demographic data of student in terms of their date of birth and prior academic performance was collected from 'student profile register' of the department.There were no dropouts during the study.

\section{Computer assisted learning (CAL) module used in the study}

CAL module under studywas designed and developed by faculties of our department.It contained various sections on human embryology. The first section had text under various subsections beginning with general embryology and followed by systemic embryology. The text wasself-explanatory and relevant diagrams were incorporated in it; a pattern not very different from traditional textbooks or notes. However, a feature that made it strikingly different from these traditional tools was incorporation of animation videos of events and 3D models with text and diagrams. After reading through the text, students could click on a link and visualize events as $2 \mathrm{D}$ or $3 \mathrm{D}$ animations. Simultaneously streaming audio commentaryhas also beenincorporated into the CAL module. When used as instruction material, instructor first explained students in lecture hall about orientation and a particular event happening during prenatal human development. This was followed by visualization of same event with another audio commentary that is incorporated in the CAL module itself. It was ascertained that the module under study did not exclude any core areas of learning as per the current curriculum of university we are affiliated to.

In second section are photographs of models pertaining to embryology, which has been integral part of teaching even in traditional ways. These photographs are labelled and have been included to help students for quick revisions and also as methods for testing themselves after completion of a particular section. There are also sections on glossary of terminology frequently used, a time line of events starting from day one of fertilization, applied aspects of human embryology and finally a section on quiz for evaluation. Screenshots of the CAL module under study are shown in fig 1 (A to F). 

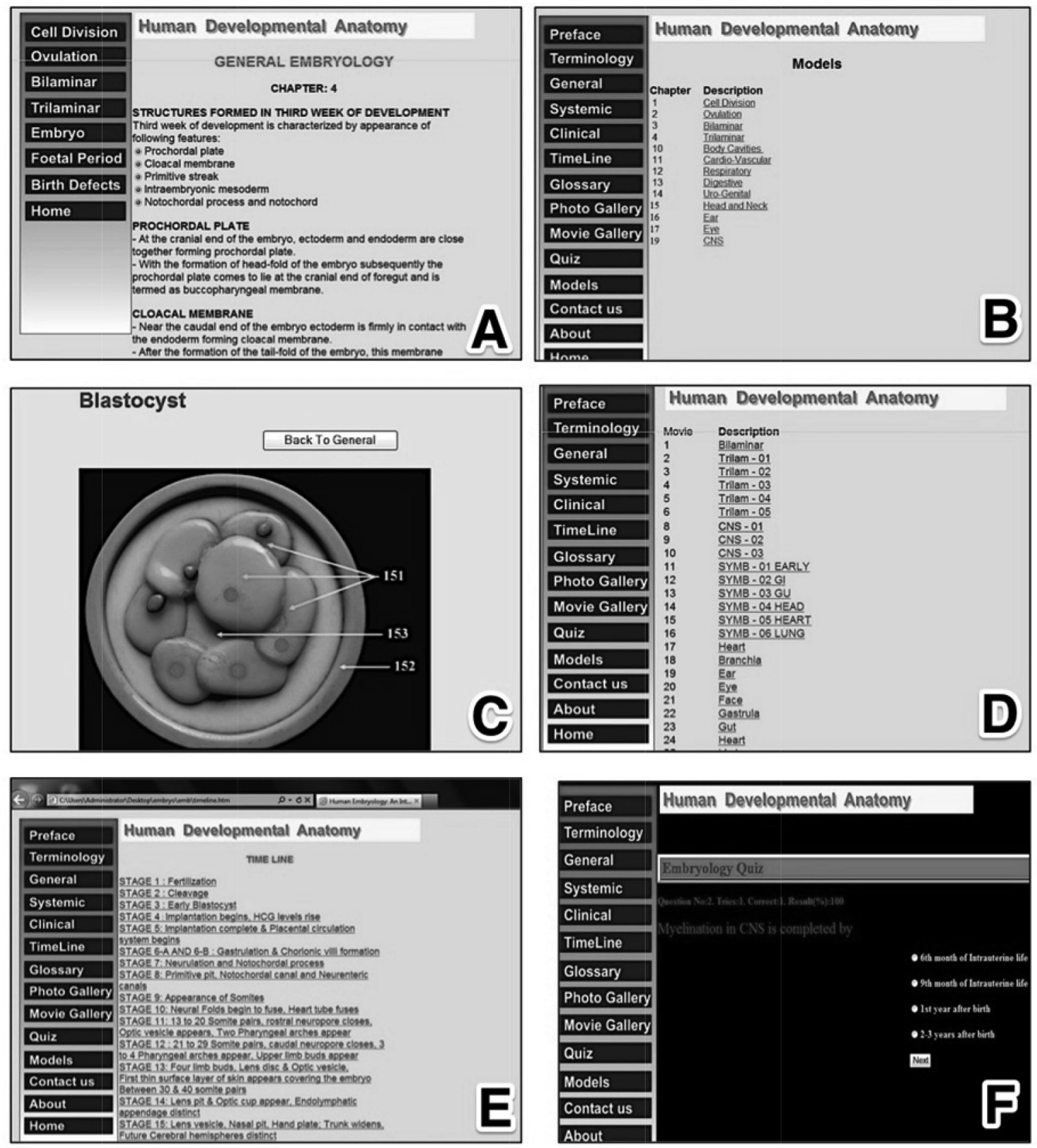

Figure 1. Snapshots of the computer module used in the study. A - Section on description of general embryology; B - Model study section; C - Model showing blastocyst; D - Index of movies and animations; E - Time-line of events; $\mathbf{F}$ - Section of quiz.

\section{Method of intervention}

Our institute follows 'academic year' pattern rather than a more popular 'semester' pattern. Students are assessed in anatomy by a single examination at the end of academic year. Since students tend to forget the portions covered early in academic year, our department conducts one--month--long revision classes prior to university exams. The purpose of these revision classes is to quickly recapitulate all aspects of anatomy that has already been learned throughout one year.

This study was conducted during these revision sessions. This particular time was chosen for study because our objective was to supplement the traditional method of learning with CAL and not to use it as an alternative.

Revision sessions for gross and microscopic anatomy 
were conducted by traditional methods. During four sessions of 45 minutes each spanning over two days dedicated for embryology, test and control group were instructed separately. Instructors allocated for control group used only chalk, board and models. In test group CAL module was usedas instruction material using overhead projection system. Instructions for both groups were instructor guided.Instruction materials for both groups were structured to ensure that both groups received same material, the only difference being mode of delivery. Care was also taken not to give any direct hints to answers of questions to be used in posttest. Both groups had same amount of time available for self-study and they were free to discuss with each other at times other than while attending revision sessions. Instructors participating in revision sessions were allocated randomly and researchers of the study were not involved in instruction sessions of any group to prevent possible bias

Following completion of study and after conducting post-test for both groups, four more such sessions on embryology using CAL module were conducted for control group students alone. This measure was taken to exclude unethical bias in context of their performance in university examinations. Expressed written consent was obtained from all human subjects participating in this study. Training officer in-charge of our department overlooked the study from its conception, study protocol design and execution for excluding any violation of current ethical guidelines.

\section{Evaluation}

CAL module was evaluated both objectively and subjectively. A pre-test was conducted for both groups of students before commencement of study. It consisted of 50 multiple choice answer questions (MCQ's). Post-test was conducted at the end of study and similarly had 50 MCQ's. Every question of both pre and post test fetched 0.5 marks.

Opinion of students and all instructors involved in conducting revision classes were obtained using anonymous questionnaire. Heading used were subject interest, appropriateness of teaching materials, overall student satisfaction with teaching received and effectiveness as the CAL module as self-learning module. Options provided for response wereas average, good and excellent (see table 3 ).

\section{Statistical analysis}

After calculating mean, range and standard deviation of demographic characteristics and prior academic performance,Levene's test and analysis of variance (ANOVA) was used to compare the equality of means of two (see table 1). Similarly mean and standard deviations were calculated for pre and post-test scores and significance in difference of mean scores was calculated (see table 2). Five percent $(\mathrm{P}<0.05)$ was taken to be cut offpoint of significance. Computer software used for statistical analysis was statistical package for social sciences (SPSS 19).No statistical test was used for analysis of responses to anonymous questionnaire.

\section{RESULTS}

Control and test groups were similar in terms of sex ratio, age and previous academic performance with no statistically significant difference (Table 1). Mean pretestscores showedno significant difference between the two groups. Post-test reflected that mean scores of test group were better than control group and the difference was statistically significant (Table 2).

Response to questionnaire showed that more than half the students and instructors graded CAL module under study as 'excellent' under all heads(Table 3).

Table 1.Characteristics of students used in the study in terms of their age and prior academic performance. Total sample size was 128 with 64 in each group. Significance in equality of means calculated using Levene's test and ANOVA. $\mathrm{P}<0.05$ was considered significant.

\begin{tabular}{|c|c|c|c|c|}
\hline \multirow[b]{2}{*}{ Group } & \multicolumn{2}{|c|}{ Age in years } & \multicolumn{2}{|c|}{$\begin{array}{l}\text { Score of XII in per- } \\
\text { centage }\end{array}$} \\
\hline & $\begin{array}{l}\text { Mean } \pm \\
\mathrm{SD}\end{array}$ & $\begin{array}{l}\text { Mean } \\
\text { SE }\end{array}$ & $\begin{array}{l}\text { Mean } \pm \\
\mathrm{SD}\end{array}$ & Mean SE \\
\hline Test group & $\begin{array}{l}18.59 \pm \\
0.81\end{array}$ & 0.10 & $\begin{array}{l}87.89 \pm \\
5.52\end{array}$ & 0.69 \\
\hline Control group & $\begin{array}{l}19.82 \pm \\
1.04\end{array}$ & 0.13 & $\begin{array}{l}85.38 \pm \\
8.36\end{array}$ & 1.04 \\
\hline $\begin{array}{l}\text { Significance in } \\
\text { difference of } \\
\text { means (P Value) }\end{array}$ & \multicolumn{2}{|l|}{0.469} & \multicolumn{2}{|l|}{0.49} \\
\hline
\end{tabular}


Table 2. Comparison of pre \& post-test scores. Fifty multiple-choice questions were used for both tests with each correct answer awarded as 0.5 marks and no negative markings. Significance in equality of means calculated using Levene's test and ANOVA. $\mathrm{P}<0.05$ was considered significant.

\begin{tabular}{|l|l|l|l|}
\hline & Mean \pm SD & SE of Mean & $\begin{array}{l}\text { Significance in difference of } \\
\text { means (P Value) }\end{array}$ \\
\hline Control Pre test & $19.31 \pm 1.692$ & 0.230 & \multirow{2}{*}{0.562} \\
\cline { 1 - 2 } Control Post test & $19.52 \pm 2.538$ & 0.345 & \multirow{2}{*}{0.000} \\
\cline { 1 - 3 } Subject Pre test & $19.47 \pm 2.271$ & 0.264 & 0.233 \\
\cline { 1 - 3 } Subject Post test & $20.48 \pm 2.000$ & 0.233 & \\
\hline
\end{tabular}

Table 3. Students' and instructors' response to questionnaire provided for subjective assessment of CAL module under study; Values represent percentage of total respondents.

\begin{tabular}{|c|c|c|c|c|c|c|c|c|c|c|c|c|c|}
\hline \multirow[t]{2}{*}{ S No } & & \multicolumn{3}{|c|}{ Subject interest } & \multicolumn{3}{|c|}{$\begin{array}{l}\text { Appropriateness } \\
\text { of CAL module as } \\
\text { teaching materials }\end{array}$} & \multicolumn{3}{|c|}{$\begin{array}{l}\text { Overall satisfaction } \\
\text { with teaching received }\end{array}$} & \multicolumn{3}{|c|}{$\begin{array}{l}\text { Possible effective- } \\
\text { ness as self learn- } \\
\text { ing module }\end{array}$} \\
\hline & & + & ++ & +++ & + & ++ & +++ & + & ++ & +++ & + & ++ & +++ \\
\hline 1 & Students & 13 & 29 & 58 & 11 & 22 & 67 & 6 & 20 & 74 & 09 & 23 & 69 \\
\hline 2 & Instructors & 09 & 24 & 67 & 04 & 16 & 80 & - & - & - & 5 & 16 & 79 \\
\hline
\end{tabular}

+: Average; ++: Good; +++: Excellent

\section{DISCUSSION}

Advantages of use of CAL modules in supplementing theoretical teaching are step-by-step demonstration of processes, attracting and holding class attention, the presentation of scenarios and physical settings, the representation of real cases and complex situations and the analysis of movement ${ }^{[15]}$.CAL in medical education can help to liberate students from the burden of the rote learning of facts, and enhance the role of reason and imagination in the learning process ${ }^{[10]}$. An ideal resource would be the one that is able to anticipate logical paths a student may follow and provide the necessary degree of resources, interactivity and have a proper instructional design.In addition students find computers fun, in part because they are more interactive than books.Important disadvantage of learning something as essential and as extensive as human anatomy by computer is that the thought processes of the learner tend to be narrowly directed by the program. Computer programs feed us someone else's logic, instead of encouraging us to develop our own; real learning means inventing our own ways of solving problems.
Chalk and talk are ages old and time-tested methods of teaching, learning and classroom management ${ }^{[16]}$. Didactic lectures in embryology cannot be done away with but the common problem faced by an embryology instructor is to make students understand simultaneous and overlapping complex sequence of events that occur during development. CAL modules can be very helpful in this regard. Not many studies could be found in current literature for comparison in 'use of CAL modules used for embryology instruction'. Few that are available have clubbed embryology with gross anatomy ${ }^{[17,18]}$. Most of other such studies done on gross anatomy had a good model to compare with i.e. dissection versus CAL module ${ }^{[19,20]}$. A model similar to ours was adopted by Pereira et al and termed it as 'blended learning strategies' but this study too was concerned with gross anatomy ${ }^{[8]}$. One lesson learnt in this strategy was the time factor. Since we supplement and not replace the traditional methods of teaching and learning, the absolute time spent in classroom tends to increase, this was in accordance with the conclusions of Vichitvejpaisal et al ${ }^{[11]}$. Another study shows that traditional teaching supported with CAL module improves performance in both gross and neuroanatomy ${ }^{[1]}$. 
World wide web is now available to most part of global population including third world countries ${ }^{[21]}$. Medical students at our institute have 24-hour access to Internet and thus also have access to innumerable computer graphics, animations, movies and 3D models of human embryology. The plethora of information available on the web is overwhelming, and both students and staff need to be taught how to manage it effectively. Medical schools must develop clear strategies to address the issues raised by these technologies ${ }^{[22]}$. Our objective while developing this CAL module was not to provide them with anything new but to compile the information and technology already available them into core areas of learning.

In our study the students selected had comparable age and academic background. The pre-test results of the randomly allocated groups were very similar indicating that their level of competency prior to study was similar inembryology (Table 1). Significantly higher post--test scores of test group indicates better efficacy of CAL module in comparison to traditional methods of instruction alone (Table 2). Since the whole batch had already received instructions using traditional methods during regular classes throughout the year, it is not possible tocomment on two methods independently based on our study. Only inference that can be drawn is traditional methods supplemented by CAL module is superior to traditional methods alone. The fact that control group had received a repeat exposure is also reflected by their minimal change in mean scores from pre to post test (19.31 to 19.52).

Though most students responded in their questionnaire that this could be 'good' resource for self-study, its true effectiveness as a self-study module depends on multiple other factors like computer literacy, competency, frequency and duration of use of the module ${ }^{[23]}$; even after assuming the availability

We collected sufficient evidence to warrant the use of CAL module in embryology classes and we intend to use it as a supplementary tool in regular classes throughout the year. All the students to be enrolled in next batch will also be provided with a copy of this CAL module for the purpose of self-study, revision and evaluation as a self-study resource. In this regard we share the views of Nicholson et al whose findings also stand in contrast to the handful of previous randomized controlled trials that evaluated the effects of computergenerated 3-D anatomical models on learning ${ }^{[20]}$. We identified that embryology is an area in education of medical undergraduates where CAL modules can be used effectively. Given our positive results, we believe that further research is warranted concerning the use of CAL modules in other fields of medical education as well.

\section{CONCLUSIONS}

CAL modules when supplemented with traditional methods of teaching and learning improve the understanding of human embryology in medical undergraduates. Use of such modules take some more time but they are definitely time-effective when total time spent by the students to achieve similar level of understanding by only traditional methods are taken into consideration. More studies are required to comment upon the effectiveness of this CAL module as a self-studymaterial.

\section{ACKNOWLEDGEMENT}

Prof S Ghatak, Prof Sushil Kumar, Prof T Vijay Sagar and Prof B K Mishra of Army medical corps, India, for their contribution towards design of computer module.

\section{REFERENCES}

1. Elizondo-Oma-a RE, Morales-Gómez JA, Guzmán SL, Hernández IL, Ibarra RP, Vilchez FC. Traditional teaching supported by computer-assisted learning for macroscopic anatomy. The Anatomical Record Part B: The New Anatomist. 2004; http://dx.doi.org/10.1002/ar.b.20019

2. Rosenberg H, Grad HA, Matear DW. The effectiveness of computer-aided, self-instructional programs in dental education: a systematic review of the literature. Journal of Dental Education. 2003;67(5):524- 32.

3. Lewis MJ. Computer-assisted learning for teaching anatomy and physiology in subjects allied to medicine. Medical teacher. 2003;25(2):204-7.http://www.webcitation. org/6L6X8di1a. http://dx.doi.org/10.1080/713931397http:// dx.doi.org/10.1080/0000000000000000000a

4. Greenhalgh T. Computer assisted learning in undergraduate medical education. BMJ: British Medical Journal. 2001;322(7277):40. ttp://dx.doi.org/10.1136/ bmj.322.7277.40

5. Tam M, Hart AR, Williams S, Heylings D, Leinster S. Is learning anatomy facilitated by computer-aided learning? A review of the literature. Medical Teacher. 2009;31(9):e393-e6. http://dx.doi.org/10.1080/01421590802650092

6. McNulty JA, Sonntag B, Sinacore JM. Evaluation of computer-aided instruction in a gross anatomy course: A six-year study. Anatomical sciences education. 2009;2(1):28. http://onlinelibrary.wiley.com/doi/10.1002/ase.66/ abstract. http://dx.doi.org/10.1002/ase.66

7. Pereira JA, Pleguezuelos E, Meri A, Molina-Ros A, 
Molina-Tomás MC, Masdeu C. Effectiveness of using blended learning strategies for teaching and learning human anatomy. Medical education. 2007;41(2):189-95. http:// dx.doi.org/10.1111/j.1365-2929.2006.02672.x

8. Walsh RJ, Bohn RC. Computer-assisted instructions: a role in teaching human gross anatomy. Medical Education. 1990;24(6):499-506. http://dx.doi. org/10.1111/j.1365-2923.1990.tb02665.x

9. Older J. Anatomy: A must for teaching the next generation. The Surgeon. 2004;2(2):79-90. http://dx.doi.org/10.1016/ $\underline{\text { S1479-666X(04)80050-7 }}$

10. Anderson G. Achieving Teaching Excellence: A Step-byStep Guide: Gerald Anderson; 2009.

11. Eyster RH, Martin C. Successful Classroom Management: Real-world, Time-tested Techniques for the Most Important Skill Set Every Teacher Needs: Sourcebooks, Inc.; 2010.

12. Nieder GL, Nagy F. Analysis of medical students' use of Web-based resources for a gross anatomy and embryology course. Clinical Anatomy. 2002;15(6):409-18. http://dx.doi. org/10.1002/ca.10067

13. Nieder GL, Parmelee DX, Stolfi A, Hudes PD. Team-based learning in a medical gross anatomy and embryology course. Clinical Anatomy. 2005;18(1):56-63. http://dx.doi. org/10.1002/ca.20040

14. McNulty JA, Halama J, Espiritu B. Evaluation of computeraided instruction in the medical gross anatomy curriculum. Clinical Anatomy. 2004;17(1):73-8. http://dx.doi. org/10.1002/ca.10188

15. Nicholson DT, Chalk C, Funnell WRJ, Daniel SJ. Can virtual reality improve anatomy education? A randomised controlled study of a computer-generated threedimensional anatomical ear model. Medical Education. 2006;40(11):1081-7. http://dx.doi.org/10.1111/j.13652929.2006.02611.x

16. James J. The global digital divide in the Internet: developed countries constructs and Third World realities. Journal of Information Science. 2005;31(2):114-23. http://dx.doi. org/10.1177/0165551505050788

17. Ward J, Gordon J, Field MJ, Lehmann HP. Communication and information technology in medical education. The Lancet. 2001;357(9258):792-6. http://dx.doi.org/10.1016/ $\underline{\text { S0140-6736(00)04173-8 }}$

18. Chumley-Jones HS, Dobbie A, Alford CL. Webbased learning: sound educational method or hype? A review of the evaluation literature. Academic Medicine. 2002;77(10):S86-S93. http://dx.doi.org/10.1097/00001888200210001-00028 